\title{
Linear effects in ATB movement
}

\author{
Benjamin Bruening and Eman Al Khalaf*
}

\begin{abstract}
Munn (2001), Citko (2005), and others argue that in ATB movement initial and non-initial gaps exhibit asymmetries in reconstruction effects and weak crossover: only the initial ATB gap shows reconstruction and weak crossover. Munn argues that these asymmetries are due to the nature of the gap: the initial ATB gap is a real gap, while non-initial gaps are parasitic gaps. Parasitic gaps are generally claimed to show no reconstruction or weak crossover (e.g., Nissenbaum 2000). We re-examine reconstruction in ATB movement and parasitic gap constructions and show that in most cases the putative asymmetries between gaps are not real, and when there is an asymmetry it is due to linear order and not to the nature of the gap. We conclude that both ATB movement and parasitic gap constructions involve full copies in all gaps.
\end{abstract}

Keywords. ATB movement; parasitic gaps; weak crossover; reconstruction; linear order

1. Introduction. It has long been thought that in ATB movement the initial gap and the subsequent gaps show a number of asymmetries in reconstruction and weak crossover. Munn (2000; 2001) and Citko (2005) show that unlike the initial ATB gap, non-initial gaps are insensitive to reconstruction effects for binding condition A:

(1) (Citko 2005, 493, (44))

a. * [Which picture of himself ${ }_{i}$ ] did Mary sell _ and $\mathrm{John}_{i}$ buy _?

b. [Which picture of himself ${ }_{i}$ ] did $\mathrm{John}_{i}$ sell _ and Mary buy _?

In addition, reconstruction effects for binding condition $\mathrm{C}$ show up only in the initial gap according to the judgments reported by Munn and Citko:

(2) (Citko 2005, 494, (45))

a. * [Which picture of $\mathrm{John}_{i}$ ] did he like $_{-}$and Mary dislike _ ?

b. [Which picture of $\mathrm{John}_{i}$ ] did Mary like _ and he ${ }_{i}$ dislike _?

Munn cites examples like those below which show that weak crossover appears only with respect to the initial ATB gap:

*We thank Peter Cole, Alan Munn and Satoshi Tomioka for helpful comments. We also thank graduate students at Department of Linguistics and Cognitive Science at UD for grammaticality judgments. Authors: Benjamin Bruening, University of Delaware (bruening@udel.edu) \& Eman Al Khalaf, University of Jordan (e.alkhalaf@ju.edu.jo). 
(3) (Munn 2001, 374, (10a,c))

a. [Which $\left.\operatorname{man}_{i}\right]$ did you hire and $_{-}$his ${ }_{i}$ boss fire $\_$?

b. * [Which $\left.\operatorname{man}_{i}\right]$ did his ${ }_{i}$ boss fire _ and you hire _?

On the basis of these asymmetries, Munn (2001), Zhang (2010), and others argue that noninitial gaps in ATB movement do not involve movement at all, but are occupied by a null element that is not a trace. Munn contends that this null element is a parasitic gap (PG). Munn's analysis challenges the often taken-for-granted theory of ATB movement as movement from all gaps, creating what is referred to as a forking chain (the forking chain analysis).

2. New Data and Proposal. In this paper, we re-examine the asymmetries between ATB gaps which have been reported in the literature. We surveyed thirteen speakers on examples of ATB movement and parasitic gap constructions which involve violations of binding conditions A and $\mathrm{C}$ and weak crossover. Speakers' judgments show that (i) in many cases the asymmetries are not real, (ii) where they are, the asymmetry is due to linear order not the nature of the gap. We also find evidence of reconstruction into parasitic gap sites. We therefore argue that both ATB movement and parasitic gap constructions involve extraction from all gaps (adopting the forking chain analysis for both).

3. Condition C. Starting with the asymmetries in reconstruction for condition $\mathrm{C}$ of the type in (4), our speakers find no asymmetry between initial and non-initial gaps. Ten out of thirteen find both sentences grammatical. Only two rate $(4 b)$ better.

(4) a. * [Which picture of $\left.\mathrm{John}_{i}\right]$ did he ${ }_{i}$ like _ and Mary dislike _ ?

b. [Which picture of $\mathrm{John}_{i}$ ] did Mary like _ and he ${ }_{i}$ dislike _?

To test whether linear order plays a role in the asymmetry for those few speakers who find one, we tested examples of PG constructions where the PG precedes the real gap:

(5) a. This is the type of story about Obama $_{j}$ that people who hear $p g_{i}$ think he ${ }_{j}$ will be angry about $t_{i}$.

b. This is the type of story about Obama $_{j}$ that people who tell him him $_{j}$ to ignore $p g_{i}$ always end up talking about $t_{i}$.

In Munn's analysis, (5a) should be ungrammatical. The judgments we got challenge this prediction. Nine out of thirteen speakers report no difference between $(5 a, b)$; two find (5a) better, and one finds $(5 b)$ better.

The judgments seem to identify two groups of speakers: speakers who find no contrast between the gaps and speakers who reconstruct to initial gaps only (very few speakers). To account for these results, we propose that generally, speakers only copy the head of the filler into gap positions:

Which picture of $\mathrm{John}_{i}$ did he ${ }_{i}$ like [which picture] and Mary dislike [which picture]?

Under some conditions some speakers copy the head plus any complement in the first gap, but only the head in subsequent gaps. For these speakers, the identity of the copy seems to decrease with linear distance from the filler: 
(7) Which picture of $\mathrm{John}_{i}$ did Mary like [which picture of John] and he ${ }_{i}$ dislike [which picture]?

We thus propose that the variation in judgments on Condition $\mathrm{C}$ has to do with whether a full copy or a partial copy fills the non-initial gap, not the nature of the gap itself (real vs. parasitic).

4. Condition A. Turning to the asymmetries in reconstruction for binding condition A, we collected judgments on examples like the one below:

(8) a. * * Which picture of himself $\left.{ }_{i}\right]$ did Mary sell _ and $\mathrm{John}_{i}$ buy _?

b. [Which picture of himself ${ }_{i}$ ] did $\mathrm{John}_{i}$ sell _ and Mary buy _?

Our speakers divide into two groups. The first group found a violation in the initial gap or a non-initial gap equally acceptable (six out of thirteen found the sentences equally grammatical, one finds them equally ungrammatical). The second group found a violation in a non-initial gap more acceptable (five found ( $8 \mathrm{a}$ ) better as previous literature reported, while one speaker finds ( $8 \mathrm{~b}$ ) better).

Note that the example here involves a picture-NP. In fact, all the examples cited in the literature are of this sort. In such contexts, anaphors are known to be exempt from condition A. Exempt anaphors are thought to be licensed by the closest perspective center (Pollard and Sag 1992, Reinhart and Reuland 1993). When a perspective center is established, a violation in the initial conjunct becomes acceptable:

(9) $\mathrm{John}_{i}$ is upset. Which picture of $\operatorname{himself}_{i}$ will Mary find _ and he ${ }_{i}$ then have to explain _?

We propose that the variation in speakers' judgments on examples that involve an exempt anaphor is due to speaker variation in requiring the closest possible perspective taker to be the antecedent for an exempt anaphor. Those who find violations in the initial gap and non-initial gaps equally grammatical seem to have no preference, while those who do not tolerate a violation in the initial conjunct seem to require that the closest NP be the antecedent.

We also tested cases of exempt anaphors in picture NPs in PG constructions where the PG precedes the real gap. In the PG analysis, only the real gap show reconstruction effects, so (10a) should be ungrammatical and (10b) grammatical. The results we got do not match this prediction. Three out of thirteen speakers judged (10a) better than (10b), while the rest found no difference. This is consistent with our proposal above.

(10) a. [How many portraits of herself ${ }_{i}$ ] did [the woman $_{i}$ who commissioned $p g$ ] end up asking that artist to take $t$ back?

b. [How many portraits of himself ${ }_{i}$ ] did [the woman who commissioned $p g$ ] end up asking [that artist $]_{i}$ to take $t$ back?

Much more telling are examples with non-exempt anaphors. We tested reconstruction with anaphors in argument position and PPs like the ones below:

(11) a. * [Criticize himself $\left.{ }_{i}\right], \operatorname{John}_{i}$ will _ but Mary won't _.

b. * [Criticize himself ${ }_{i}$ ], Mary will _ but John ${ }_{i}$ won't _. 
(12) a. * [Over himself $\left.{ }_{i}\right], \mathrm{John}_{i}$ pulled a blanket _ and Mary threw a rug _.

b. $\quad *$ [Over himself $\left.{ }_{i}\right]$, Mary pulled a blanket _ and $\mathrm{John}_{i}$ threw a rug _.

Our results are that speakers divide into two groups: five out of thirteen speakers report that $(12 \mathrm{a}, \mathrm{b})$ are equally ungrammatical/marginal, while six out of thirteen found (12a) better (and two found them equally grammatical).

The same results were found with PG constructions where the PG precedes the real gap:

(13) a. * It is only himself ${ }_{i}$ that [people who know $p g_{i}$ think $\mathrm{John}_{i}$ should blame $t_{i}$ ].

b. * It is only themselves ${ }_{i}$ that [people ${ }_{i}$ who blame $p g_{i}$ will realize John has conned $t_{i}$ ].

Eight out of thirteen judge both (13a, b) unacceptable, while three out of thirteen found (13a) slightly better and two out of thirteen judged them both grammatical. We should note that PGs must involve a full copy; otherwise, (13a) would be grammatical for all speakers.

With non-exempt anaphors, speakers divide into two groups. One group finds no contrast between the initial and non-initial gap; reconstruction into both is required. The other group seems to allow a binding violation in non-initial gaps. We therefore generalize the analysis we proposed above for Condition $\mathrm{C}$. We propose that there are two sorts of reconstruction: full reconstruction, that is reconstruction of full copies, and reconstruction with vehicle change in the non-initial gaps. In particular, we propose that most speakers require all gaps to be exact copies of the filler:

(14) * Over himself ${ }_{i}, \mathrm{John}_{i}$ pulled a blanket [over himself] and Mary threw a rug [over himself].

However, some speakers require the first gap to be an exact copy of the filler, but subsequent gaps can marginally undergo vehicle change. Over himself reconstructs as over himself in the initial gap, and as over him in the non-initial gap. Speakers who allow this then permit an apparent binding violation in non-initial gaps:

(15) Over himself $i, \mathrm{John}_{i}$ pulled a blanket [өver himself] and Mary threw a rug [over him].

For these speakers (a minority), the asymmetries with non-exempt anaphors seem to be due to variation in identity between the gap and the filler; identity seems to decrease with linear distance from the filler for some speakers, which makes a binding violation in a non-initial gap acceptable.

To wrap up, the putative asymmetries between ATB gaps in reconstruction for binding condition A are either not real (with exempt anaphors), or they are due to linear order: vehicle change is allowed in non-initial gaps but not in the initial gap. Importantly, ATB gaps and PGs behave the same, with the important factor being linear order, not PGs versus "real" gaps.

5. Weak Crossover. We repeat example (3), in which only the initial gap shows weak crossover:

(16) a. [Which $\left.\operatorname{man}_{i}\right]$ did you hire and his $_{i}$ boss fire _?

b. $\quad *\left[\right.$ Which $\left.\operatorname{man}_{i}\right]$ did his $_{i}$ boss fire _ and you hire _?

This asymmetry simply follows from linear accounts of weak crossover that have already been proposed (Chomsky 1976, Higginbotham 1980, Shan and Barker 2006). We formalize this condition below: 
(17) A quantifier Q can bind a pronoun $\mathrm{P}$ as a variable only if some A-position occupied by $\mathrm{Q}$ precedes $P$.

The extraction in (16a), according to the condition above, does not result in weak crossover because there is an A-position that is occupied by (a copy of) which man that precedes his, namely object of hire. In (16b), however, the extraction induces a weak crossover violation because there is no A-position occupied by which man which precedes his.

Given this condition, we predict that if the PG precedes the real gap, WCO should reverse. An example that would test the validity of this prediction follows:

(18) a. What kind of father ${ }_{i}$ do teachers who have to send his ${ }_{i}$ child home to $p g_{i}$ always end up despising $t_{i}$ ?

b. What kind of father ${ }_{i}$ do teachers who meet $p g_{i}$ have no trouble sending his child $_{i}$ home to $t_{i}$ ?

However, speakers polled found no contrast between (18a) and (18b). Both were found equally grammatical or equally ungrammatical. We suspect that many speakers dislike parasitic gaps in relative clauses modifying subjects. Also, in these examples, the PG is part of a relative clause. Relative clauses often do not show weak crossover (Lasnik and Stowell 1991).

We thus constructed sentences that avoid the problems associated with an example like (18), using gerunds as subjects:

(20) a. * Which official ${ }_{i}$ did his $_{i}$ boss's firing $p g_{i}$ make reporters scramble to get an interview with $t_{i}$ ?

b. Which official ${ }_{i}$ did the boss('s) firing $p g_{i}$ make his ${ }_{i}$ friend try to intercede for $t_{i}$ ?

Informal polling for the above examples shows that our prediction is correct. Weak crossover reverses when the PG precedes the real gap, confirming that the asymmetry between gaps in weak crossover is due to linear order and not the nature of the gap. PGs also show weak crossover when they precede the real gap.

6. Conclusion. In this paper, we re-investigated putative asymmetries between ATB gaps in reconstruction effects and weak crossover. We argued against the claim that the asymmetries are due to ATB gaps differing in nature, where non-initial gaps are not real gaps. The judgments we collected reveal that most of the claimed asymmetries are due to linear order and not to the nature of the gaps. Significantly, we find evidence of full reconstruction into PG sites. We propose that an analysis in which extraction occurs from all gaps is on the right track, for both PG constructions and ATB movement. Linear asymmetries result from partial copying or vehicle change in noninitial gaps. We suggest that such an analysis should make use of left-to-right derivations (Phillips 1996, 2003; Bruening 2014), but we do not spell out such an analysis here and leave the issue for future research (but see Al Khalaf (2015) for a sketch of such an analysis). 


\section{References}

Al Khalaf, Eman (2015), Coordination and Linear Order. Ph.D. thesis, University of Delaware. available at http://udspace.udel.edu/handle/19716/17494.

Bruening, Benjamin (2014), "Precede-and-command revisited." Language 90(2): 342-388.

Chomsky, Noam (1976), “Conditions of rules of grammar." In Noam Chomsky, ed., Essays on Form and Interpretation, North Holland. Amesterdam.

Citko, Barbara (2005), "On the Nature of Merge: External Merge, Internal Merge, and Parallel Merge." Linguistic Inquiry 36(4): 475-496.

Higginbotham, James (1980), “Reciprocal Interpretaton.” Journal of Linguistic Research 1(97117).

Lasnik, Howard, and Tim Stowell (1991), “Weakest Crossover.” Linguistic Inquiry 22(4): 687-720.

Munn, Alan (2000), “Three Types of Coordination Asymmetries.” In Kerstin Schwabe and Ning Zhang, eds., Ellipsis in Conjunction, Tubingen, vol. 418 of Linguistische Arbeiten (Max Niemeyer Verlag).

Munn, Alan (2001), "Explaining Parasitic Gap Restrictions.” In Peter Culicover and Paul Postal, eds., Parasitic Gaps, Massachusetts:MIT Press, pp. 369-392.

Nissenbaum, Jon (2000), “Investigations of covert Phrase Movement.” Ph.D. Dissertation. Cambridge: MIT.

Phillips, Colin (1996), Order and Structure. Ph.D. thesis, Massachusetts Institute of Technology. Distributed by MIT Working Papers in Linguistics, Cambridge, Mass.

Phillips, Colin (2003), “Linear Order and Constituency.” Linguistic Inquiry 34(1): 37-90.

Pollard, Carl, and Ivan Sag (1992), "Anaphors in English and the scope of the Binding Theory." Linguistic Inquiry 23(261-303).

Reinhart, Tanya, and Eric Reuland (1993), "Reflexivity.” Linguistic Inquiry 24(4): 657-720.

Shan, C.C., and Chris Barker (2006), "Explaining crossover and superiority as left-to-right evaluation." Linguistics and Philosophy 29: 91-134.

Zhang, Niina N. (2010), Coordination in Syntax. Cambridge; New York: Cambridge University Press. 